\title{
Are long-distance migrant passerines faithful to their stopover sites?
}

\author{
Paulo Catry, Vitor Encarnação, António Araújo, Peter Fearon, Anne Fearon, Michael Armelin and Peter Delaloye
}

Catry, P., Encarnação, V., Araújo, A., Fearon, P., Fearon, A., Armelin, M. and
Delaloye, P. 2004. Are long-distance migrant passerines faithful to their stopover sites? - J. Avian Biol. 35: 170-181.

\begin{abstract}
Long-distance migrant passerines are well known to often display high levels of philopatry to breeding and wintering grounds. One could expect that similar selective pressures and similar navigation skills would result in their being faithful to stopover sites, a pattern that has been described for several populations of migratory waders and waterfowl. In this paper, we develop the argument that passerines should suffer from higher costs and receive lower benefits from stopover site faithfulness than waterfowl and waders. Based on Alerstam's (1979) "optimal drift strategy" theory and other considerations, we predict that passerines should have lower stopover site fidelity than geese and waders, and that site faithfulness should decrease with increasing distance from either end of the migratory journey. We present results from a long-term study on the stopover ecology of migrant passerines in southern Portugal that support these predictions and show that, for species and populations that neither nest nor winter in this country, few individuals are faithful to the stopover site. On the other hand, populations that included individuals at (or near to) the start or the end of the migratory journey, had much higher return rates. We could not find any evidence that species linked to scarce habitats, such as wetlands, were more site faithful. Our results are in agreement with several other reports, but in apparent contrast to previous conclusions resulting from some studies involving Old World warblers. These differences are discussed and it is argued that there is no solid evidence to suggest that site fidelity should be important for passerines at stopovers far away from breeding or wintering grounds, meaning that there is a large within-individual variability in the precise migratory routes and stopover sequence used each year.
\end{abstract}

P. Catry (correspondence), Unidade de Investigação em Eco-Etologia, Instituto Superior de Psicologia Aplicada, Rua Jardim do Tabaco 44, 1149-041, Lisboa, Portugal \& Edward Grey Institute of Field Ornithology, Department of Zoology, University of Oxford. Oxford OX1 3PS, UK. E-mail: paulo.catry@netc.pt.V. Encarnação and A. Araújo, Instituto da Conservação da Natureza. Rua Filipe Folque 46, 5․ 1050-114 Lisboa, Portugal. P. Fearon and A. Fearon, 39 Ilford Avenue, Crosby, Liverpool L23 7YE, UK. M. Armelin, Rua Mouzinho de Albuquerque 11, Murches, 2750 Cascais, Portugal. P. Delaloye, 34 Watford Road, Croxley Green, Harts WD3 3BJ, UK.

Philopatry of migrants to their summer or wintering grounds is a permanent source of wonder to all of those who ever took an interest in birds. Besides the fascination it raises, this issue can have implications in several distinct fields, such as the conservation biology of migrants (e.g. Salathé 1991, Cantos and Tellería 1994, Sherry and Holmes 1996), orientation and navigation (Alerstam 1979, Berthold 1991) and general migratory strategies (Baker 1978, Alerstam and Lindström 1990, Houston 1999).
Migratory birds of many different groups, including passerines, are well known to often show both natal and breeding site philopatry (Baker 1978, Greenwood and Harvey 1982, Holmes and Sherry 1992). Such fidelity is likely to confer advantages linked to prior ownership of territories, as well as to previous knowledge of foraging locations, good potential nest sites, predators and potential breeding partners (Baker 1978, Greenwood and Harvey 1982). Several of these advantages will also be important outside nesting areas and high winter site 
fidelity has been shown in several migratory passerines (Nisbet and Medway 1972, Price 1981, Kelsey 1989, Holmes and Sherry 1992), as well as in other groups of birds (e.g. Evans and Townshend 1988, Robertson and Cooke 1999).

If long-distance migrants can display breeding and winter site fidelity, and therefore show remarkable navigational abilities during migratory journeys that span thousands of kilometres, it could be expected that similar skills and the prevailing selective pressures could result in their being faithful to stopover sites. However, in some situations the relative costs of being faithful to an area might outweigh the corresponding benefits, and when this happens site fidelity should be reduced, or disappear altogether. The costs of philopatry mostly arise from additional flying time (to correct for any wind drift effect during migration) and/or from a greater need for selectivity of wind conditions at departure, with a consequent loss of time.

At least some groups of relatively well studied migratory birds, such as swans, geese and waders, often show a high fidelity to certain main (and sometimes also minor) stopover sites (e.g. Gullestad et al. 1984, Smith and Houghton 1984, Harrington et al. 1988, Gudmundsson and Lindström 1992, Fox et al. 2002). Few studies have addressed the issue of stopover site fidelity in passerines, either theoretically or empirically. The main published articles give apparently contradictory results, with evidence of virtually no site fidelity coming from the New World (Nisbet 1969, Winker and Warner 1991), contrasting with suggestions of high stopover philopatry in Old World warblers (Cantos and Tellería 1994, Merom et al. 2000, but see Dowsett-Lemaire and Dowsett 1987, Dierschke 2002).

We suggest that there are several reasons why we should expect stopover site fidelity to be lower in passerines, and particularly in long-distance passerine migrants, in comparison to birds such as geese and waders.

First, suitable stopover sites are probably in greater supply to birds that are mostly terrestrial, such as the majority of passerines. Even passerines generally associated with wetlands probably are more flexible in their habitat selection and might possibly even refuel (or at least safely rest while maintaining weight) in dry habitats (as suggested, for example, by Schaub and Jenni 2001 for reed warblers Acrocephalus scirpaceus). Most waders and geese generally are more selective in relation to habitat.

Second, waders and geese tend to migrate in flocks (and in family groups, as is the case in geese), and therefore may have many opportunities to learn about the best stopover sites from older birds. Many longdistance migrant passerines, on the other hand, generally migrate singly and often during night (Alerstam 1990, Berthold 1993). Hence, they will probably acquire knowledge of good stopover sites at a slower rate. Such a disadvantage will be further increased by their relatively short life spans and by the fact they generally use a much larger number of stopover sites during each migration.

Third, typical air speeds of migrating small passerines are lower than air speeds of waders or waterfowl (e.g. Bruderer and Boldt 2001), and therefore passerines are more sensitive to wind conditions. This factor could have two types of implications: (a) Based on a theoretical model, Alerstam (1979) predicted that, to minimise flying time and energy consumption, migrating birds facing variable winds, when far away (several days or flights) from their goal, should allow themselves to be partly drifted by the winds, and increase compensation only as they approach the final destination (Alerstam 1979). The benefits of partial compensation (as opposed to complete compensation) when away from the final target should be greater for birds with low relative (to the wind) air speeds. This means that, if the "optimal drift strategy" (Alerstam 1979, Liechti 1995) is being used, or at least if migrant birds are not fully compensating for wind drift (see Zehnder et al. 2001 for empirical evidence), the migratory route will depend on the wind conditions met with during each season. (b) Weather conditions are one of the most important factors that condition migratory activity (e.g. Richardson 1990). Migrants have a continuum of options, and as concerns weather selectivity, two extremes. If the birds are highly selective, the duration of the stay at each stopover can be almost as unpredictable as the weather (note that wind conditions can be as important as fat reserves in the adjustment of departures; e.g. Liechti and Bruderer 1998). In such a case, it probably pays to skip certain stopovers when conditions are good, and stop more often and stay longer when conditions are bad. Skipping stopovers will tend to reduce site fidelity, even if the migratory route is maintained from one year to another. If, on the other hand, migrants show little selectivity in relation to the wind, the effect of wind-drift referred to above will be reinforced, and this again could result in low site fidelity.

Fourth, site fidelity, in swans and geese, has the potential benefit of allowing the reunification of accidentally broken family bonds. In these birds, the pairs stay together all year-round, and reunification of lost pairs have clear benefits for the individuals (e.g. Robertson and Cooke 1999). Such a benefit of non-breeding site-fidelity is believed to be generally absent in migratory passerines and waders, as in these birds partnerships are generally not maintained outside the breeding season.

How should stopover site fidelity compare to breeding or winter site fidelity? This is difficult to predict, as many different costs and benefits under variable circumstances would need to be taken into consideration. However, for 
birds that travel in small steps and use a large number of stopovers (as most long-distance passerine migrants do) it is likely, for the reasons explained above (requirement of full wind-drift compensation and high weather selectivity), that the relative costs of philopatry to staging areas are large, when many suitable alternatives are available. Each (faithful) bird often uses only one breeding and one wintering site, that it can have chosen carefully after rather extensive sampling. However, to select a large number of preferred stopover sites would imply extensive prospecting all along the migratory route, and it seems unlikely that a bird would find enough time to do that in its first, or consecutive, migratory journey(s). Even if the bird is mostly faithful to some major and particularly favourable stopover sites found on a previous journey, it seems unlikely that all previous stopovers will be used again.

Based on the considerations above, we predict that: (1) stopover fidelity in long-distance migratory passerines should be generally lower than in birds such as waders and geese, and (2) stopover site fidelity should be lower than breeding or wintering site fidelity in birds (such as passerines) that use many stopovers during migration. In what concerns winter site fidelity, this prediction does not apply to species or populations that show an itinerant behaviour in winter and that have a low local recurrence rate (see Salewski et al. 2000, 2002). (3) Stopover site fidelity should be greater at staging sites closer to the wintering or the breeding areas than in locations far from either end of the migratory journey. A fourth prediction (already proposed by other authors; e.g. Cantos and Tellería 1994) states that: (4) higher stopover fidelity should be found in species that depend on scarce, patchily distributed habitats (such as wetlands). Finally, we suggest that: (5) populations or individuals that successfully refuel at the stopover site should be more likely to return during following seasons. This hypothesis is based on the idea that successful refuelling is an indicator of good environmental conditions for foraging at the stopover site.

In this paper we use a large data set from a long-term field study, carried out at a coastal lagoon in southern Portugal, to assess the general importance of stopover fidelity of long-distance passerine migrants at this site, and to test the predictions stated above.

\section{Material and methods}

\section{Study area and general field procedures}

The Santo André lagoon is located at the southern West coast of Portugal. The lagoon is about $3 \mathrm{~km}$ wide, and comprises an area of marshland with reeds Phragmites and rushes Scirpus spp. in its southeastern end, where this study took place. The marsh area is surrounded by pine Pinus spp. woodland, scrub and pastures. Since the late 1970s ringing operations have been regularly carried out at this site. From 1992 procedures have been standardised, so that the main net lanes are maintained in the same positions in the marsh year after year, covering a core area of ca. 8 ha. The number and position of nets set in the woodland and scrub have been more variable, but the main ringing effort has been concentrated in the same relatively small general area (ca. 9 ha). In this study, we have used data collected between 1992 and 1997.

In each year, during most of the summer and in early autumn (see Table 1) nets were operated daily from sunrise till noon, and only sporadically in the evening (almost exclusively to trap roosting swallows). Except for a few days at the end of September and in early October, only on truly exceptional occasions were we prevented from operating the mist nets by unsuitable weather. Tape-lures to induce landfall of over-flying night migrants (Schaub et al. 1999) were never used during this study. Every bird, newly trapped, was ringed and, whenever possible, aged and sexed following the criteria defined in Svensson (1992). Maximum wing-chord was measured using a wing ruler and mass was taken by using a Pesola spring-balance. The amount of subcutaneous fat stores was assessed visually by using a six-point (0 to 5) scale. All retrapped birds were processed in a similar way and their ring number recorded. All birds were released at the ringing site, within a short distance $(<500 \mathrm{~m})$ from the trapping locations.

\section{Study species}

For this study we used all long-distance migrant passerine species that were caught in good numbers (and often retrapped within the same season) when stopping over at Santo André: bluethroat Luscinia svecica, sedge warbler Acrocephalus schoenobaenus, reed warbler A. scirpaceus, grasshopper warbler Locustella naevia and willow warbler Phylloscopus trochilus. Many other long-distance migrants are regularly caught at Santo André. These other species were not included in the study because: (1) in spite of having occasional between-year retraps, they were only caught in very small numbers (e.g. aquatic warbler Acrocephalus

Table 1. Fieldwork seasons in Santo André that provided data for this study. Captures and ringing were carried out on every day from the first to the last date during each year.

\begin{tabular}{lll}
\hline Year & First Day & \multicolumn{1}{c}{ Last day } \\
\hline 1992 & 5 August & 19 September \\
1993 & 9 August & 26 September \\
1994 & 1 August & 11 September \\
1995 & 27 July & 25 September \\
1996 & 25 July & 28 September \\
1997 & 30 July & 7 October \\
\hline
\end{tabular}


paludicola), (2) they had very low within-year retraps, suggesting low recapture probabilities, and no betweenyear retraps (e.g. whinchat Saxicola rubetra), or (3) the local breeding populations could not be told apart from passing migrants (e.g. Savi's warbler Locustella luscinioides).

Sedge, grasshopper and willow warblers neither nest nor winter in Portugal. Birds occurring in Santo André mostly originate from western and northern Europe, and winter in Africa south of the Sahara (Cantos 1992 and local unpubl. recoveries). Some bluethroats winter in Portugal, while reed warblers nest in good numbers along the coast. Therefore, we separated the birds of each of these species into two groups: one composed by birds that were almost all passing migrants and another where "migrants" and "local" birds were probably mixed: a) short-winged bluethroats (wing-length shorter than $73 \mathrm{~mm}$ ) of the subspecies L. s. namnetum (Cramp 1988, Constant and Eybert 1995a) make up the majority of the wintering population of this species in Portugal (Constant and Eybert 1995a). Therefore, the "shortwinged" (SW bluethroats) birds caught at Santo André would have included both passing migrants and locally wintering individuals. On the other hand, bluethroats with a wing longer than $72 \mathrm{~mm}$ would be mostly, if not all, L. s. cyanecula, a subspecies believed to winter mainly in Africa (Cramp 1988). Although we know that some birds of this latter group ("long-winged" LW birds) can also winter in Portugal, very few (if any) in our sample would have done so locally, as the species is scarce in Santo André during the cold months. b) Reed warblers are trans-saharan migrants. They nest at Santo André (Catry 1997), although the majority of the birds caught during the summer and autumn are believed to be passing through, which is suggested by the large numbers and daily fluctuations in the trap totals. According to Bibby and Green (1981), in Portugal certain migrants can be distinguished by taking maximum-chord wing-lengths of $>65 \mathrm{~mm}$ for juveniles and $>66 \mathrm{~mm}$ for adults. Although we know there can be occasional exceptions to this rule, we defined a longwinged ("LW reed warbler") group based on these criteria. The short-winged ("SW reed warbler") group would have included both local birds and passage migrants.

\section{Definitions and statistical analyses}

A bird is said to have been recaptured only when it was trapped on a later date compared to the day of ringing. Recaptures on the same day were not considered because ringing procedures might have temporarily upset the normal behaviour of the bird, making it more prone to be recaptured on a net immediately after release.
Fattening rates (grams per day) of migrants were calculated as the difference in mass measured in the last and the first capture, divided by the corresponding time interval. Following Bibby and Green (1981), fattening rates were only calculated for birds caught three or more days apart. This restriction reduces the effect of errors caused by diurnal mass fluctuations and also minimises the "initial mass loss effect" that migrants usually suffer after arriving to a new stopover (e.g. Lindström 1995).

To calculate return (or recurrence) rates from the between-year recapture rates, one needs to know the recapture probability for the birds present at the study site in years subsequent to initial ringing, as well as the annual survival rate for individuals of that species. Dividing the observed between-year recapture rates by the estimated recapture probability and then by the annual survival rates provide the necessary corrections. We used the overall within-year recapture rates (see Results) as a minimum estimate of recapture probability. This produces an underestimated recapture probability, because in the year of ringing, birds can only be recaptured after first capture and marking, while in subsequent years they can be recaptured from arrival until departure from the stopover site. We adopted this methodology, instead of the recently developed sophisticated approach described by Schaub et al. (2001), because the recapture data for some species was clearly insufficient and it would have been extremely timeconsuming to try to fit capture-recapture models to all seven study populations. But most important, we think it preferable to err on the conservative side, and produce overestimated return rates (resulting from division of real between-year recapture rates by underestimated recapture probabilities), since the point being made in this paper is that return rates are very low anyway. Annual survival estimates were taken from Peach et al. (2001). We could not find a published survival estimate for bluethroats, and so we used the estimate for a species of the same genus, the nightingale Luscinia megarhynchos (Peach et al. 2001).

The effect of selected variables on the probability of an individual being recaptured in the same or in a subsequent year was assessed by the use of logistic regressions. Model significance was evaluated using likelihood-ratio tests (Norusis 1994). The logistic regression coefficient $(\beta)$ is presented with the test statistics. All means are presented with standard errors. Sample sizes in different tests vary because: (1) not all variables were measured in all birds, (2) recaptures in 1992 (the first year of the study) were not introduced in the data-base because birds from 1991 were not available for recapture, and (3) birds captured in the last year of the study could not be recaptured in subsequent years. 


\section{Results}

\section{Stopover behaviour}

The overall proportion of individual birds that, within the same migratory season, were recaptured at the study site ranged from $3.2 \%$ to $30.8 \%$ in different species or populations (Table 2). For birds that were recaptured at least once, the mean minimum length of the stay ranged from 3.1 to 11.8 days for different species (Table 3). These are underestimates since on many occasions individuals would not have been caught in both the first and last days of the stopover (Schaub et al. 2001).

Of the five species studied, in only two, the sedge and the willow warblers, did the majority of the individuals stopping over at Santo André manage to accumulate fat stores, which is shown by a mean daily fattening rate significantly greater than 0 (Table 4). It is interesting to note on passing that, our results are in contrast with the work done by Bibby and Green (1981), also at Santo André, in the late 1970s. These authors found that migrating reed warblers accumulated fat, but sedge warblers did not, precisely the opposite from what we report. Given that our field and analytical procedures were similar to theirs in all known details, we can only conclude that local conditions must have changed since the completion of their study.

For reed and sedge warblers, the probability that an individual stayed beyond the capture day was influenced by its fat stores when first trapped. Birds with larger fat stores were less likely to be recaptured. No such effect could be detected for the remaining three species (Table 5).

\section{Between-year recapture rates}

With the exception of the grasshopper warbler, all study species showed a limited fidelity to the stopover site (Table 6). This includes two species (sedge and willow warblers) for which no individuals are known to either breed or winter in Portugal, and therefore for which Santo André can only be a migratory stopover site.

Table 2. Overall within-season recapture rates for different species and populations occurring at Santo André. Recaptured birds were those caught at the study site at least one day after the date of ringing. Reed warblers and bluethroats are divided into "short" and "long-winged" subgroups or populations (see text for further explanations).

\begin{tabular}{lccc}
\hline Species & $\begin{array}{c}\text { Total } \\
\text { ringed }\end{array}$ & $\begin{array}{c}\text { Number } \\
\text { recaptured }\end{array}$ & $\begin{array}{c}\text { Recapture } \\
\text { rate (\%) }\end{array}$ \\
\hline SW Bluethroat & 178 & 48 & 27.0 \\
LW Bluethroat & 128 & 27 & 21.1 \\
SW Reed warbler & 2,974 & 916 & 30.8 \\
LW Reed warbler & 1,161 & 194 & 16.7 \\
Sedge warbler & 606 & 47 & 7.8 \\
Grasshopper warbler & 476 & 15 & 3.2 \\
Willow warbler & 2,742 & 149 & 5.4 \\
\hline
\end{tabular}

Table 3. Estimated minimum duration of stopover (in days) for birds that were caught on more than one different day within a season. Reed warblers and bluethroats are divided into "short" and "long-winged" subgroups or populations (see text for further explanations).

\begin{tabular}{lccr}
\hline Species & $\begin{array}{c}\text { Mean minimum } \\
\text { duration of } \\
\text { stopover }\end{array}$ & Median & $\mathrm{n}$ \\
\hline SW Bluethroat & $9.6 \pm 0.9$ & 8 & 48 \\
LW Bluethroat & $8.2 \pm 1.3$ & 7 & 27 \\
SW Reed warbler & $11.8 \pm 0.3$ & 9 & 916 \\
LW Reed warbler & $7.1 \pm 0.6$ & 5 & 194 \\
Sedge warbler & $3.1 \pm 0.4$ & 2 & 47 \\
Grasshopper warbler & $5.6 \pm 1.1$ & 4 & 15 \\
Willow warbler & $4.0 \pm 0.3$ & 3 & 149 \\
\hline
\end{tabular}

Table 4. Daily fattening rates of different migratory species stopping over at Santo André in the years 1993-1997. Reed warblers and bluethroats are divided into "short" and "longwinged" subgroups or populations (see text for further explanations).

\begin{tabular}{lccr}
\hline Species & $\begin{array}{c}\text { Mean fattening } \\
\text { rate }\left(\mathrm{g} \text { day }^{-\mathrm{r}}\right)\end{array}$ & Median & $\mathrm{n}$ \\
\hline SW Bluethroat & $-0.02 \pm 0.02$ & 0.00 & 36 \\
LW Bluethroat & $0.06 \pm 0.04$ & 0.07 & 21 \\
SW Reed warbler & $0.01 \pm 0.01$ & 0.01 & 640 \\
LW Reed warbler & $0.01 \pm 0.02$ & 0.02 & 112 \\
Sedge warbler & $0.13 \pm 0.05^{*}$ & 0.11 & 20 \\
Grasshopper warbler & $-0.09 \pm 0.11$ & 0.00 & 8 \\
Willow warbler & $0.11 \pm 0.02^{*}$ & 0.13 & 61 \\
\hline
\end{tabular}

* indicates a fattening rate significantly greater than zero.

However, between-year recapture rates in Santo André were consistently low, for the five species and populations that were known (or almost certainly known) to include only passage migrants, varying between 0 and $1.2 \%$ of the birds ringed from 1992 to 1996 (Table 6).

SW bluethroats (mostly L. S. namnetum) showed a higher between-year recapture rate than LW $L$. $s$. cyanecula (Table 6; Yates corrected $\chi_{1}^{2}=4.96, \quad \mathrm{P}<$ 0.05). Such differences were not the result of the sample of long-winged individuals being biased towards both adult and male birds. When pooling the entire bluethroat data set, neither age nor sex had an effect on the probability of return (Logistic Regression, $\mathrm{G}_{2}^{2}=0.4$, $\mathrm{P}=0.8, \mathrm{n}=242$ ). Between-year recapture rates for

Table 5. The effect of the body fat stores when first captured on the probability of a bird staying over at least one night in Santo André.

\begin{tabular}{lcccr}
\hline Species & $\begin{array}{c}\beta-\text { Effect of } \\
\text { fat reserves }\end{array}$ & $\mathrm{G}_{1}^{2}$ & $\mathrm{P}$ & $\mathrm{n}$ \\
& -0.10 & 0.2 & 0.6 & 162 \\
SW Bluethroat & -0.05 & 0.1 & 0.8 & 116 \\
LW Bluethroat & -0.03 & 96.9 & $<0.001$ & 2,729 \\
SW Reed warbler & -0.12 & 4.6 & $<0.05$ & 1,129 \\
LW Reed warbler & -0.21 & 4.8 & $<0.05$ & 578 \\
Sedge warbler & 0.25 & 2.2 & 0.1 & 397 \\
Grasshopper warbler & -0.03 & 0.1 & 0.7 & 2,032 \\
Willow warbler & & & & \\
\hline
\end{tabular}


Table 6. Overall between-year recapture rates for different species at Santo André. Reed warblers and bluethroats are divided into "short" and "long-winged" subgroups or populations (see text for further explanations).

\begin{tabular}{lccc}
\hline Species & $\begin{array}{r}\text { Total } \\
\text { ringed }\end{array}$ & $\begin{array}{c}\text { Number } \\
\text { recaptured }\end{array}$ & $\begin{array}{c}\text { Recapture } \\
\text { rate (\%) }\end{array}$ \\
\hline SW Bluethroat & 200 & 14 & 7.0 \\
LW Bluethroat & 118 & 1 & 0.8 \\
SW Reed warbler & 2,793 & 126 & 4.5 \\
LW Reed warbler & 1,244 & 15 & 1.2 \\
Sedge warbler & 498 & 1 & 0.2 \\
Grasshopper warbler & 432 & 0 & 0.0 \\
Willow warbler & 3,365 & 3 & 0.1 \\
\hline
\end{tabular}

Table 7. Overall between-year recapture rates for each age and sex class of bluethroats ("long" and "short-winged" birds pooled)

\begin{tabular}{lccc}
\hline Class & $\begin{array}{c}\text { Total } \\
\text { ringed }\end{array}$ & $\begin{array}{c}\text { Number } \\
\text { recaptured }\end{array}$ & $\begin{array}{c}\text { Recapture } \\
\text { rate (\%) }\end{array}$ \\
\hline Adult males & 27 & 1 & 3.7 \\
Adult females & 15 & 1 & 6.7 \\
Juvenile males & 116 & 4 & 3.4 \\
Juvenile females & 84 & 4 & 4.8 \\
\hline
\end{tabular}

each age and sex-class are shown in Table 7. The greater propensity for cyanecula bluethroats to carry on with migration (see also references in the Methods section) was further suggested by the fact that, on average, the LW group carried more fat when first caught at Santo André than the SW group (mean fat scores of $1.12 \pm$ $0.11, \mathrm{n}=124$, and $0.53 \pm 0.06, \mathrm{n}=203$, respectively, ANOVA: $\left.\mathrm{F}_{1,325}=26.1, \mathrm{P}<0.001\right)$. This difference is maintained when restricting the analysis to juvenile birds, to avoid the probable effect of age on both winglength and fat stores. On the other hand, within-year recapture rates for SW and LW birds were similar (Table 2; Yates corrected $\chi_{1}^{2}=1.09, \mathrm{P}=0.3$ ).

Table 8. Estimated maximum return rates of migrants obtained by dividing the between-year recapture rate by the within-year recapture rate, and by estimated survival rates (results are likely to be overestimates).

\begin{tabular}{lc}
\hline Species & $\begin{array}{c}\text { Estimated } \\
\text { maximum } \\
\text { return rates } \\
(\%)\end{array}$ \\
\hline Migrants certainly known to be on passage: & 5.4 \\
Sedge warbler & 0 \\
Grasshopper warbler & 4.9 \\
Willow warbler & 10.6 \\
Pied flycatcher (data from Veiga 1986) & \\
Migrants very likely to be on passage: & 9.1 \\
LW Bluethroats & 12.9 \\
LW Reed warblers & \\
Groups including both passing migrants and & \\
locally or regionally wintering or & 61.8 \\
breeding birds: & 26.2 \\
SW Bluethroats & \\
SW Reed warblers & \\
\hline
\end{tabular}

JOURNAL OF AVIAN BIOLOGY 35:2 (2004)
For reed warblers, differences were also found between SW and LW groups. SW birds had a higher between-year recapture rate than the LW group (Table 6; Yates corrected $\left.\chi_{1}^{2}=26.2, \quad \mathrm{P}<0.0001\right)$. Also, similarly to what we found for the bluethroat, LW birds carried more fat than SW ones (mean fat scores of $1.46 \pm 0.04$, $\mathrm{n}=1,521$ and $1.01 \pm 0.02, \mathrm{n}=3,724$, respectively. ANOVA, $\left.F_{1,5243}=105.3, P<0.001\right)$, and had a smaller probability of being recaptured within one season (Table 2; Yates corrected $\left.\chi_{1}^{2}=84.1, \mathrm{P}<0.0001\right)$. Again, the differences are maintained when restricting the analyses to juvenile birds, to remove the possible effects of age on fat scores, stopover duration and wing -length.

Using both groups of reed warblers, the fattening rate of an individual in Santo André did not influence the probability of being recaptured in following years (Logistic Regression, $\beta=0.62, \mathrm{G}_{1}^{2}=0.14, \mathrm{P}=0.7, \mathrm{n}=$ 427). There were too few valid cases to repeat the analysis only for LW birds, or for any other of the study species.

In LW reed warblers, the between-year recapture rate of adults $(2.8 \%, \mathrm{n}=217)$ was higher than that of juveniles $\left(0.9 \%, \mathrm{n}=1,027\right.$; Yates corrected $\chi_{1}^{2}=3.9$, $\mathrm{P}<0.05)$. For other species, sample sizes for adults were generally quite small, and adult recapture rates were never higher than for juveniles.

\section{Discussion}

The estimates of return rates presented in Table 8 are inflated because recapture probabilities were underestimated (see Methods), and because some returning birds had more than one opportunity (in different years) to be recaptured. In spite of attempts to eliminate any locally breeding reed warblers, or wintering bluethroats, from the "long-winged" groups of birds, we cannot be certain of having been fully successful in doing so, and therefore, this might be another factor inflating return rate estimates of birds stopping over. The main point being made in this paper is that fidelity to the stopover site is very low, and therefore, if return-rates are inflated estimates, this point is reinforced. On the other hand, variations (even if they were relatively small) in capture effort from one year to the next at Santo André (change in the number of nets and dates of ringing) could have slightly depressed between-year recovery rates. Overall, we feel confident that our estimates give a good idea of the order of magnitude of the return rates, and that comparisons between different sub-groups within a species are robust, because data was collected using exactly the same procedures for all categories and the differences reported are clear.

Our results could be generally challenged if Santo André was only a marginal, or an emergency stopover site for the migrants studied, unsuitable under normal 
conditions (e.g. Dierschke 2002). We find this unlikely for several reasons. First, most birds caught in the marsh, and included in the study, are indeed typically linked to wetlands during migration (Bairlein 1983). Second, at least two species succeeded in fattening at the study site, and individuals or species that did not gain mass were not less likely to be recaptured in subsequent years. Third, many birds stopped over for several days, and (at least in reed and sedge warblers) individuals were making state-dependent decisions, on whether to stay or to leave, based on their body condition. Fourth, these results were broadly similar to the ones reported for pied flycatchers Ficedula hypoleuca in Central Spain (Veiga 1986, see more below).

Estimated return rates of presumed or known passage migrants varied between 0 and $12.9 \%$ for the species studied. The maximum estimated return rate for a species that neither nests nor winters in Portugal was $5.4 \%$ (sedge warblers). It can be concluded that only a small minority of the surviving individuals is being faithful to this stopover site.

Veiga (1986) studied the stopover ecology of pied flycatchers in Central Spain (away from breeding areas) in a 1 ha garden surrounded by a degraded ash wood. Nets were operated daily during the whole migration period in 1983 and in 1984. Of 122 pied flycatchers caught in 1983 , only one $(<1 \%)$ was retrapped the following year. Capture probability was not very low, as $15 \%$ of the 222 birds caught in both years were recaptured at least once in the days following first capture. It should also be noted that this was not a marginal site for the species, as birds stopping over succeeded in accumulating fat at a fast rate (Veiga 1986). These recapture probability values are similar to the ones obtained for long-distance migrants at Santo André, even though a different species, geographic location (inland versus coastal) and habitat (woodland versus mostly wetland) were considered.

\section{Prediction 1. Stopover fidelity in long-distance migratory passerines should be generally lower than in birds such as waders and geese}

Estimated return rates for passerines at Santo André are very low (a small minority of the birds estimated to be alive came back to the same stopover site). Unfortunately, there are virtually no studies on stopover site fidelity to which we can compare our data. Almost all the quantitative studies we could find, reporting on return rates, failed to correct for recapture probabilities. Because recapture probabilities can potentially take any values between 0 and 1, the meaning of such uncorrected results is difficult to assess. In Table 9, we present a tentative review of return rates reported in studies on geese, waders and passerines. In spite of the limitations of such data, it is clear that, while several studies found high (ca. $50-100 \%$ ) return rates in geese and waders, there are no reports of high recurrence rates for longdistance migrant passerines at stopover sites away from breeding and wintering ranges. We could find only two apparent exceptions to this pattern (Cantos and Tellería 1994, Merom et al. 2000). These two studies are discussed in more detail below.

It should be noted here that the expression "site fidelity" can have different meanings, depending on the spatial scale considered. In many studies of waterfowl and waders, site is defined as a whole sector of a estuary, for example, where birds are easily detected visually, if marked with colour-rings or neck-bands. In passerine studies such as ours, site refers only to the area where mist-nets are set up. If, for example, birds show fidelity to the Santo André lagoon complex, but not to the same area within the lagoon, we would not be able to detect them. On the other hand, the relatively high withinseason recapture rates in our study suggest a degree of fidelity to the stopover site at a spatial scale relevant to this study. Studies on geese and waders have also found a high fidelity to small sites within a larger area of suitable habitat (e.g. Ebbinge 1992).

In conclusion, Prediction 1 is supported by the available data, although more studies, particularly on waders and passerines, are needed before a final conclusion can be reached.

Prediction 2. Stopover site fidelity should be lower than breeding or wintering site fidelity in birds (such as passerines) that use many stopovers during their migration

Return rates reported in this study are much lower than return rates documented for wintering long-distance migrant passerines of the same genus (Luscinia, Acrocephalus, Locustella, Phylloscopus and Ficedula). Although this might not be an unbiased sample of the reality, the studies we could find give, correcting for differences in survival estimates, recorded or estimated return rates of 17/0.419 $=41 \%$ (Luscinia svecica), ca. 30/ $0.558=54 \%$ (Acrocephalus scirpaceus), ca. 40 to $50 /$

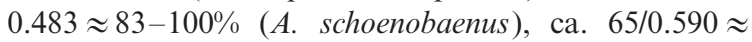
$100 \%$ (A. orientalis $), 47 \quad / .560=84 \% \quad($ A. palustris $)$, ca. $20 / 0.5=40 \%$ (Locustella certhiola), 52 to $67 / 0.389$ $\approx 100 \%$ (Phylloscopus trochiloides) and 8 to $67 / 0.501$ $\approx 16-100 \%$ (Ficedula hypoleuca; respectively, Constant and Eybert 1995b, Pearson 1972, Nisbet and Medway 1972, Kelsey 1989, Nisbet 1967, Price 1981, Salewski et al. 2000; see also Peach et al. 2001 for survival rates of these species or closely related ones). Salewski et al. (2000) report an absence of site fidelity for willow warblers wintering in the Ivory Coast, a pattern that can result from the itinerant behaviour of the species in 


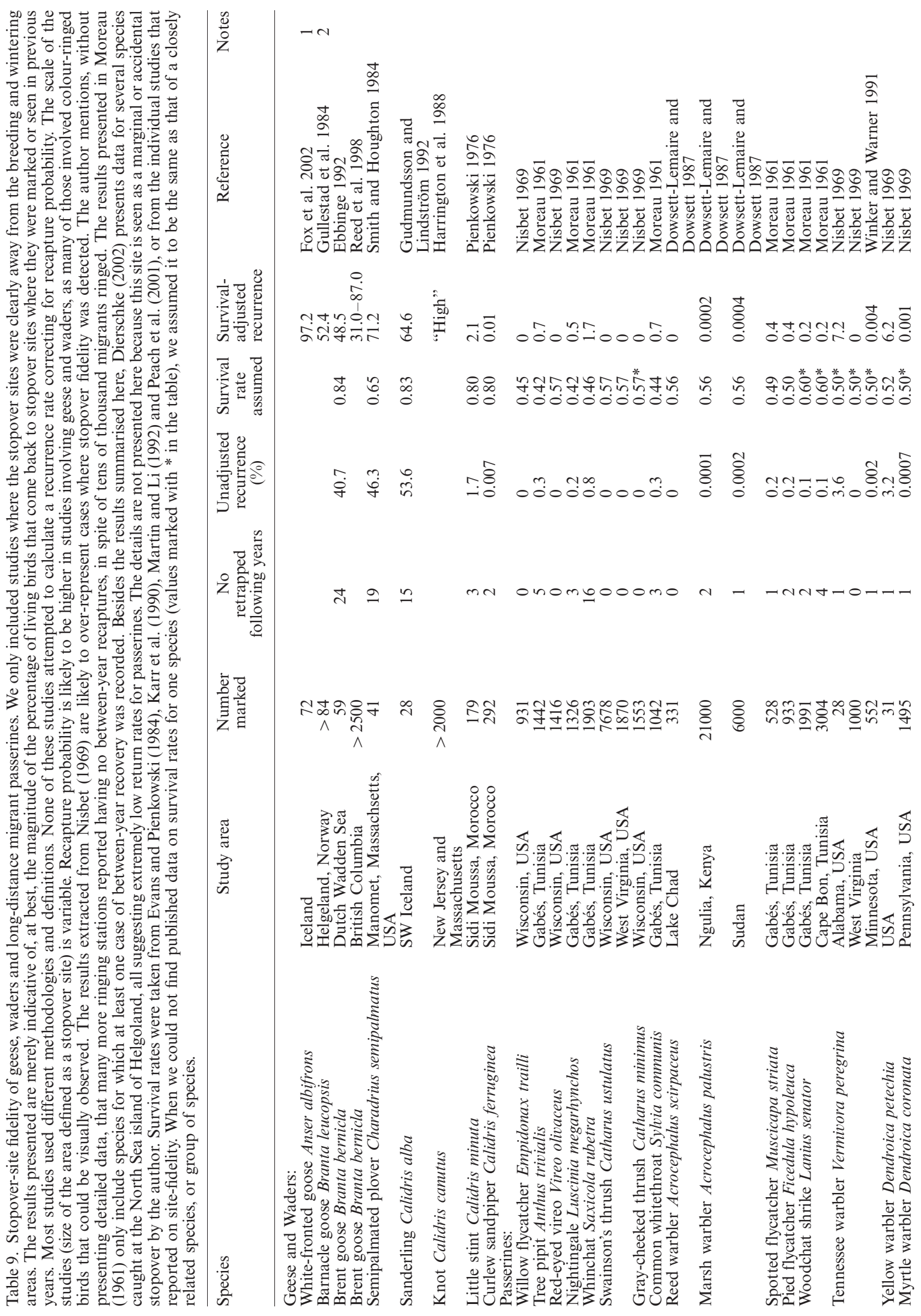




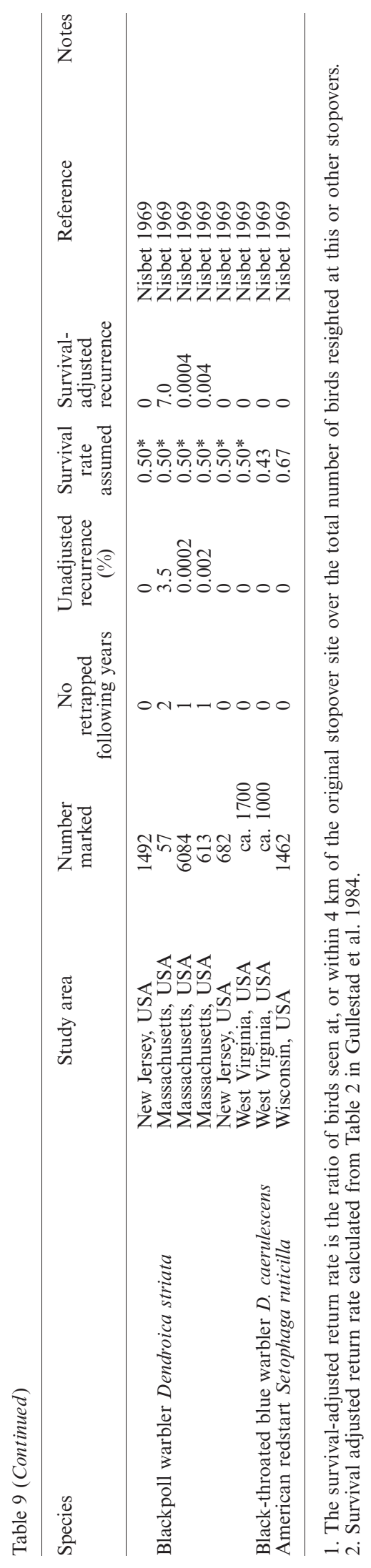

this area (Salewski et al. 2002). Since our hypothesis does not apply to populations showing itinerant behaviour, this comparison does not contradict Prediction 2. Willow warblers have been recorded having relatively high return rates $(24$ to $29 / 0.389=62-75 \%$ ) to their breeding territories (Tiainen 1983, Jakobsson 1988). Even though the cited studies are not strictly comparable to ours (for example, most studies used resightings of colour-ringed individuals), the magnitude of the differences seems rather overwhelming.

These trends are further supported by our comparisons of LW and SW groups of bluethoats and reed warblers. Although SW groups probably included many (perhaps mostly) passage migrants, besides the local breeding or wintering birds (a confounding factor which tends to hide any real differences between SW and LW classes), LW groups had lower return rates in both species (even when taking into account differences in recapture probability found in reed warblers). In conclusion, Prediction 2 is supported by the available data.

Prediction 3. Stopover site fidelity should be greater at stopover sites closer to the wintering or the breeding areas than in locations far from either end of the migratory journey

Results of the comparisons between LW and SW bluethroats and reed wablers also support this prediction. We know (see Methods) that more birds in the SW groups would be close to the start (reed warbler) or the end (bluethroat) of the migratory journey than in the LW groups, and as expected, SW groups displayed much higher site fidelity. Unfortunately it is impossible to tell whether the differences result from individuals stopping over at Santo André, or only from birds breeding or wintering there. Bluethroats of the two groups had the same within-year recapture rate and apparently the same stopover duration, and the species is scarce in Santo André during winter. These facts suggest most study birds were passing by. Considering the large differences between LW and SW groups, it seems likely that Prediction 3 might apply here.

We may also regard predictions 2 and 3 as two different aspects the same reality, within the framework of a flexible migratory strategy between two different fixed points, with incomplete compensation to winddrift (Alerstam 1979, Liechti 1995). In this case, the results of the comparisons between the different bluethroat and reed warblers groups certainly do lend strong support to the predictions, irrespective of the relative contribution of "local" and "passing" birds in the SW samples. 
Prediction 4. Higher return rates will be found in species that depend on scarce, patchily distributed habitats (such as wetlands)

If we compare the estimated return rates of the four species linked to wetlands with the willow warbler and the pied flycatcher data (Table 8), these two last species do not stand out as displaying a particularly low stopover site fidelity. Although we admit the sample size is small (6 species), the results do not seem to support the hypothesis that birds linked to scarce habitats show higher stopover site fidelity. It should be noted that wetlands really are a relatively scarce habitat in southern Portugal, particularly in the Santo André region. Clearly, more studies are needed to confirm this surprising result.

Prediction 5. Populations or individuals that successfully refuel at the stopover site should be more likely to come back in following years

This prediction does not get support from either the interspecific comparisons or the intraspecific analysis for the reed warbler. Again, more results from future studies are needed to clarify this issue.

We could find only two studies suggesting there is high stopover site fidelity for migrant passerines. The first was carried out in Spain and involved four Old World warblers (Sylviidae). Cantos and Tellería (1994) used the national data bank of ringing recoveries (considering only recaptures in mist-nets) to calculate an index of stopover site fidelity. They concluded, "stopover site fidelity is important for warblers during their migrations across the Iberian Peninsula", based on the fact that the index values for the return rates during migratory seasons were at least half as high as the ones for the breeding and winter quarters. The second study involved reed warblers at one stopover site in Israel, and used methods broadly similar to ours (Merom et al. 2000). Several explanations could help accounting for the differences between these two studies and others (see particularly Nisbet 1969, Dowsett-Lemaire and Dowsett 1987, Winker and Warner 1991, Dierschke 2002, this study): (1) both studies that reported apparently high stopover site fidelity involved species that either breed or winter in the regions where the studies took place. As suggested by the rationale behind Prediction 3, and the empirical evidence from Santo André, fidelity might be high because migrants were close to the origin or destination of their migratory movement. (2) Despite attempts by the authors to exclude (using capture and recapture dates) locally breeding or wintering individuals from the stopover analyses, some misclassifications are possible, and according to Prediction 2, these would tend to inflate estimated return rates. (3) Two of the four species in the Iberian study are relatively short-distance migrants, that might be expected (because by definition they are always closer to winter or breeding grounds) to have higher stopover site fidelity than long-distance migrants. (4) The index of return rate relative to breeding, stopover and wintering areas (given by the number of birds recovered at the ringing site divided by all recoveries in the same season), presented in Cantos and Tellería (1994), had a maximum recorded value of 0.58 (for breeding reed warblers), being generally around or below 0.50 for all the 4 species and seasons. This means that about $50 \%$ of the birds were recovered away from the original ringing sites. Knowing that alternative sites with mist-nets would be an extremely small proportion of all possible alternative sites for nonphilopatric individuals (at least in the terrestrial species), one must conclude that the vast majority of birds were not site faithful. The reasons for such an unexpected pattern for breeding and wintering individuals are unknown, but seen in this light, the results do not seem to support the contention of general site fidelity being "important". Finally, (5) the conclusion that reed warblers are highly philopatric to stopover sites, reached by Merom et al. (2000), is based on comparisons that excluded all the birds that were captured in only one year. Reasons for such an exclusion are not presented in the paper, and might need re-evaluation (Robin McLery, pers. comm.). A calculation involving all birds (from their Table 1) suggests that only $3.9 \%$ of the birds classified as transients (migrants at stopover) were recaptured in the year subsequent to ringing.

Similar sets of data are only rarely presented in the ornithological literature, in spite of the fact that many studies on stopover ecology of passerine migrants have been carried out in Europe and in North America. We suspect that the reasons for this omission are linked to the fact that between-year recapture rates, for most species and sites, are generally so extremely low (Nisbet 1969) that they have been looked upon as sporadic events (e.g. Woodward 1972, Foy 1975), and probably not worth systematic investigation. Whatever the main reasons for the differences between the two studies discussed above and the remaining evidence, it is clear that more research on this interesting issue is desired before any definite conclusions can be made.

\section{Conclusions}

Data collected in this and other stopover ecology studies suggest that long-distance passerine migrants show very low return rates to their staging areas (with the possible exception of stopovers near the breeding and/or the wintering grounds), in contrast to the high philopatry displayed in many nesting and wintering areas. 
This seems to apply not only to terrestrial species, but also to species linked to wetlands.

Although a weak test to the theories of migratory strategies in relation to the wind, our results support the idea that migrant passerines generally do not have a fixed migratory route and stopover-site sequence, and therefore can adopt flexible strategies in what concerns wind-drift compensation and/or wind selectivity.

Acknowledgements - A large number of (mostly) Portuguese and British ringers were involved in collecting the data used in this paper, and we want to thank them all. We thank Robin McLery for a useful discussion concerning the study on site fidelity of reed warblers in Israel. Lukas Jenni, José Pedro Granadeiro, Richard Phillips and an anonymous referee made useful comments on earlier drafts. Part of this study was supported by Fundação para a Ciência e a Tecnologia (FCTPortugal) through the Programa plurianual (UI\&D 331/94) and P. Catry benefited from a post-doctoral grant from FCT (Praxis XXI BPD/16304/98)

\section{References}

Alerstam, T. 1979. Wind as selective agent in bird migration. - Ornis Scand. 10: 76-93.

Alerstam, T. 1990. Bird Migration. - Cambridge University Press, Cambridge.

Alerstam, T. and Lindström, Å. 1990. Optimal bird migration: the relative importance of time, energy and safety. - In: Gwinner, E. (ed.). Bird migration: the physiology and ecophysiology. Springer-Verlag, Berlin, pp. 331-351.

Bairlein, F. 1983. Habitat selection and associations of species in European passerine birds during southward, post-breeding migrations. - Ornis Scand. 14: 239-245.

Baker, R. R. 1978. The Evolutionary Ecology of Animal Migration. - Hodder and Stoughton, London.

Berthold, P. (ed.). 1991. - Orientation in Birds. Birkhäuser, Basel.

Berthold, P. 1993. Bird Migration. A General Survey. - Oxford University Press, Oxford.

Bibby, C. J. and Green, R. E. 1981. Autumn migration strategies of reed and sedge warblers. - Ornis Scand. 12: 1-12.

Bruderer, B. and Boldt, A. 2001. Flight characteristics of birds: I. Radar measurements of speeds. - Ibis 143: 178-204.

Cantos, F. J. 1992. Migracion e invernada de la Familia Sylviidae (Orden Paseriformes, Clase Aves) en la Peninsula Ibérica. - Unpubl. PhD Thesis, Universidad Complutense de Madrid.

Cantos, F. J. and Tellería, J. L. 1994. Stopover site fidelity of four migrant warblers in the Iberian Peninsula. - J. Avian Biol. 25: 131-134.

Catry, P. 1997. Selecção do habitat pela avifauna nidificante na vegetação palustre da Lagoa de Santo André. - Portugaliae Zoologica 4: 1-8.

Cramp, S. (ed.). 1988. The Birds of the Western Palearctic Vol. V. - Oxford University Press, Oxford.

Constant, P. and Eybert, M.-C. 1995a. Données sur la reproduction et l'hivernage de la gorgebleue Luscinia svecica namnetum. - Alauda 63: 29-36.

Constant, P. and Eybert, M.-C. 1995b. Population structure of Bluethroats during a phase of recovery. - In: Bellan, D., Bonin, G. and Eming, C. (eds). Functioning and dynamics of natural and perturbed ecosystems. - Intercept Ltd., Lavoisier.

Dierschke, V. V. 2002. Kaum ein vogel kerlt zurück: geringe rastplatztreue von ziehenden landvögeln zur nordseeinsel Helgoland. - Vogelwarte 41: 190-195.
Dowsett-Lemaire, F. and Dowsett, R. J. 1987. European reed and marsh warblers in Africa: migration patterns, moult and habitat. - Ostrich 58: 65-85.

Ebbinge, B. 1992. Regulation of numbers of dark-bellied geese Branta bernicla bernicla on spring staging sites. - Ardea 80: 203-228.

Evans, P.R. and Pienkowski, M.W. 1984. Population dynamics of shorebirds. - In: Burger, J. and Olla, B.L. (eds). Shorebirds. Breeding Behavior and Populations. Plenum Press, New York and London.

Evans, P. R. and Townshend, D. J. 1988. Site faithfulness of waders away from the breeding grounds: how individual migration patterns are established. - In: Ouellet, H. (ed.). Acta XIX Congressus Internationalis Ornithologici. University of Ottawa Pess, pp. 594-603.

Fox, A. D., Hilmarsson, J. O., Einarsson, Ó., Walsh, A. J., Boyd, H. and Kristiansen, J. N. 2002. Staging site fidelity of Greenland white-fronted geese Anser albifrons flavirostris in Iceland. - Bird Study 49: 42-49.

Foy, R. W. 1975. Returns of transient warblers to a coastal station. - EBBA News 38: 128-130.

Greenwood, P. J. and Harvey, P. H. 1982. The natal and breeding dispersal of birds. - Ann. Rev. Ecol. Syst. 13: 121.

Gudmundsson and Lindström, Å. 1992. Spring migration of sanderlings Calidris alba through SW Iceland: wherefrom and whereto? - Ardea 80: 315-326.

Gullestad, N., Owen, M. and Nugent, M. J. 1984. Numbers and distribution of barnacle geese Branta leucopsis on Norwegian staging islands and the importance of the staging area to the Svalbard population. - Norw. Polarinst. Skr. 181: $57-65$.

Harrington, B. A., Hagan, J. H. and Leddy, L. E. 1988. Site fidelity and survival differences between two groups of New World red knots (Calidris canutus). - Auk 105: 439-445.

Holmes, R.T. and Sherry, T.W. 1992. Site fidelity of migratory warblers in temperate breeding and Neotropical wintering areas: implications for population dynamics, habitat selection and conservation. - In: Hagan III, J.M. and Johnston, D.W. (eds). Ecology and Conservation of Neotropical Migrant Landbirds. Smithsonian Institution Press, Washington.

Houston, A. I. 1999. Models of optimal avian migration: state, time and predation. - J. Avian Biol. 29: 395-404.

Jakobsson, S. 1988. Territorial fidelity of willow warbler (Phylloscopus trochilus) males and success in competition over territories. - Behav. Ecol. Sociobiol. 22: 79-84.

Karr, J. R., Nichols, J. D., Klimkiewicz, M. K. and Brawn, J. D. 1990. Survival rates of birds of tropical and temperate forests: will the dogma survive? - Am. Nat. 136: 277-291.

Kelsey, M. G. 1989. A comparison of the song and territorial behaviour of a long-distance migrant, the marsh warbler Acrocephalus palustris, in summer and winter. - Ibis 1989: 403-414.

Liechti, F. 1995. Modelling optimal heading and airspeed of migrating birds in relation to energy expenditure and wind influence. - J. Avian Biol. 26: 330-336.

Liechti, F. and Bruderer, B. 1998. The relevance of wind for optimal migration theory. - J. Avian Biol. 29: 561-568.

Lindström, A. 1995. Stopover ecology of migrating birds: some unsolved questions. - Israel J. Zool. 41: 407-416.

Martin, T. E. and Li, P. 1992. Life history traits of open- vs. cavity-nesting birds. - Ecology 73: 579-592.

Merom, K., Yom-Tov, Y. and McClery, R. 2000. Philopatry to stopover site and body condition of transient reed warblers during autumn migration through Israel. - Condor 102: $441-444$.

Moreau, R. E. 1961. Problems of Mediterranean-Saharan migration. - Ibis 103: 373-427, 580-623.

Nisbet, I. C. T. 1967. Migration and moult in Pallas' grasshopper warbler. - Bird Study 14: 96-103.

Nisbet, I. C. T. 1969. Returns of transients: results of an enquiry. - EBBA News 32: 269-274. 
Nisbet, I. C. T. and Medway, L. 1972. Dispersion, population ecology and migration of eastern great reed warbler Acrocephalus orientalis wintering in Malaysia. - Ibis 114: 451-493.

Norusis, M. J. 1994. SPSS Advanced Statistics. - SPSS Inc, Chicago.

Peach, W. J., Hanmer, D. B. and Oatley, T. B. 2001. Do southern African songbirds live longer than their European counterparts? - Oikos 93: 235-249.

Pearson, D. J. 1972. The wintering and migration of Palearctic passerines at Kumpala, southern Uganda. - Ibis 114: 4360.

Pienkowski, M. W. 1976. Recurrence of waders on autumn migration sites in Morocco. - Vogelwarte 28: 293-297.

Price, T. 1981. The ecology of the greenish warbler Phylloscopus trochiloides in its winter quarters. - Ibis 123: 131-144

Reed, E. T., Cooch, E. G., Goudie, R. I. and Cooke, F. 1998. Site fidelity of black brant wintering and spring staging in the Strait of Georgia, British Columbia. - Condor 100: 426-437.

Richardson, W. J. 1990. Timing of bird migration in relation to weather: updated review. - In: E. Gwinner (ed.). Bird Migration: Physiology and Ecophysiology. Springer-Verlag, Berlin, pp. 331-351.

Robertson, G. J. and Cooke, F. 1999. Winter philopatry in migratory waterfowl. - Auk 116: 20-34.

Salathé, T. (ed.) 1991. Conserving Migratory Birds. - ICBP Tech. Publ. No.12, Cambridge.

Salewski, V., Bairlein, F. and Leisler, B. 2000. Recurrence of some palearctic migrant passerine species in West Africa. - Ring. Migr. 20: 29-30.

Salewski, V., Bairlein, F. and Leisler, B. 2002. Different wintering strategies of two Palearctic migrants in West Africa - a consequence of foraging strategies. - Ibis 144: $85-93$.
Schaub, M. and Jenni, L. 2001. Stopover durations of three warbler species along their autumn migration route. - Oecologia 128: 217-227.

Schaub, M., Pradel, R., Jenni, L. and Lebreton, J. D. 2001. Migrating birds stop over longer than usually thought: an improved capture-recapture analysis. - Ecology 82: 852 859.

Schaub, M., Schwilch, R. and Jenni, L. 1999. Does tape-luring of migrating Eurasian reed warblers increase number of recruits or capture probability? - Auk 116: 1047-1053.

Sherry, T. W. and Holmes, R. T. 1996. Winter habitat quality, population limitation and conservation of NeotropicalNearctic migrant birds. - Ecology 77: 36-48.

Smith, P. W. and Houghton, N. 1984. Fidelity of semipalmated plovers to a migration stopover area. - J. Field Ornithol. 55: 247-249.

Svensson, L. 1992. Identification Guide to European Passerines. - Lars Svensson, Stockholm.

Tiainen, J. 1983. Dynamics of a local population of the willow warbler Phylloscopus trochilus in southern Finland. - Ornis Scand. 14: 1-15.

Veiga, J. P. 1986. Settlement and fat accumulation by migrant pied flycatchers in Spain. - Ring. Migr. 7: 85-98.

Winker, K. and Warner, D. W. 1991. Unprecedent stopover site fidelity in a Tennessee Warbler. - Wilson Bull. 103: 512514.

Woodward, P. W. 1972. Another return of a transient songbird. - EBBA News 35: 101-102.

Zehnder, S., Åkesson, S., Liechti, F. and Bruderer, B. 2001. Nocturnal autumn bird migration at Falsterbo, South Sweden. - J. Avian Biol. 32: 239-248.

(Received 12 August 2002, revised 19 June 2003, accepted 5 July 2003.) 